\title{
Mesoscale modelling for wind resource evaluation purposes. A test case in complex terrain
}

\author{
A. Soares ${ }^{1}$, P. Pinto ${ }^{1}$ and R. Pilão ${ }^{2}$ \\ ${ }^{1}$ MEGAJOULE, SA. \\ Rua Eng. Frederico Ulrich 2650 4470-605 Moreira da Maia (Portugal) \\ Phone: +351 22 0915480, Fax: +351 22 9488166, e-mail: ana.soares@ megajoule.pt, \\ paulo.pinto@megajoule.pt \\ ${ }^{2}$ Instituto Superior de Engenharia do Porto, ISEP \\ Rua Dr. António Bernardino de Almeida 341, 4200-072 Porto (Portugal) \\ Phone: +351 22 8340500, Fax: +351 22 9537352, e-mail: rmp@isep.ipp.pt
}

\begin{abstract}
The aim of this work was the preliminary wind resource assessment of a complex terrain site, located in Bulgaria, using a virtual wind data series, taken from mesoscale modelling Weather Research and Forecasting system (WRF). The meso-micro scale coupling was carried out applying the virtual wind data series to the point where once a local wind measurement was conducted. This way, the comparison between the two data sets, virtual and local measurement, could be done. Using the mesoscale virtual information the characterization of the wind was done for the place of study. The microscale model Wind Atlas Analysis and Application Program (WASP) was used to make the wind resource mapping and the calculation of the estimated wind resource and annual production of energy, taking into account the defined configuration for the wind farm and the turbine model chosen.

The obtained differences, in terms of the magnitude of the estimated resource and its own dominant orientation indicates that the application of mesoscale models in very complex topography terrains should be done with extreme care.
\end{abstract}

\section{Key words}

Mesoescale, WRF, WASP, Wind Farm

\section{Introduction}

The classical methods that use measurement data obtained locally and the use of microscale simulation models, represent the state of the art regarding the assessment of wind resource potential. However, its use is only possible if the site was already monitored by a local station to measure the characteristics of the wind for a representative period - minimum one year. With the great evolution of the wind energy sector verified in recent times, the need in obtaining preliminary estimates of production before the site has been representatively characterized by local measurements, is gaining increased importance. The use of "virtual" data sets obtained by mesoscale modelling, to get a first approach to the production of a particular wind farm project is a tool that although not replacing the classical methods, can make a significant contribution in this subject.

This work presents an overall mesoscale methodology approach applied on a Bulgarian complex site, the specific details of the modelling, the final results and remarks about validation, accuracy and application.

\section{Methodology}

Regional climate simulations need an extensive quantity of data, covering at least 30 years, and a computational system capable of describing in great detail the effects of local features.

In order to obtain a comprehensive large-scale climate data the NCEP/NCAR Reanalysis database is used. This project, conceived by the National Oceanic and Atmospheric Administration (NOAA) and National Centre for Environmental Prediction (NCEP, part of the National Centre for Atmospheric Research), consists of a database of global observations from various sources (standard meteorological observations, buoys, satellites, and several others) reconstructed using advanced quality control and modelling techniques [1]. This data seamlessly describes the atmosphere in several vertical levels, with a spatial resolution of 2.5 degrees.

An initial large-scale analysis is conducted to determine the year (or range of years) that best describes the average conditions in several locations across the desired area for which long term climate data is available [2].

The simulation of the regional wind climate is performed by the Weather Research and Forecasting system (WRF) [3]. This state of the art mesoscale model is currently used by numerous institutions around the world, This numerical modelling system consists of several modules especially created to ingest observational data and 
simulate atmospheric conditions. The WRF as any numerical solver depends on boundary data to depict the initial conditions of the system and maintain numerical stability during the simulation. In order to describe a complex atmospheric system, it is required to have accurate data to represent the initial state of the atmosphere and its physical boundaries, such as surface roughness, topography and land cover.

The physical boundary data is provided by the USGS 30second Global Elevation Data (United States Geological Survey and University Corporation for Atmospheric Research). This dataset provides terrain elevation information in a horizontal grid of 30 arc seconds (approximately $1 \mathrm{~km}$ ), derived from several raster and vector sources of topographic information [4].

The land cover data is provided by the Global Land Cover Characteristics Data Base (USGS, National Center for Earth Resources Observation and Science - EROS, Joint Research Centre of the European Commission). It consists of a $1 \mathrm{~km}$ resolution global land cover characteristics dataset derived from global observations $[5,6]$.

As a result from the mesoscale simulation, the annual average wind statistics for the site (wind speed and direction) for several heights above ground level (a.g.l.) are estimated, for the defined computational spatial resolution. Recommended horizontal resolutions are normally not higher than 3 to $1 \mathrm{~km}$, due to model and inputs accuracy. The results can be presented in terms of wind resource mapping but also in terms of a single point time series or statistical results - "virtual data series", per height (a.g.l.), as an annual wind rose and wind speed histogram.

The "virtual" wind data series can be used as an input for a microscale flow model simulation. This numerical modelling allows the increase of the spatial resolution from the mesocale ( 3 to $1 \mathrm{~km}$ ) to only a dozen of meters, allowing the efficient use of the mapped wind resources for wind farm micrositing and energy estimate purposes. The microscale wind flow modelling was performed with the Wind Atlas Analysis and Application Program (WASP) [7] code.

The WASP is still the state of the art software code for microscale modelling of wind resources and overall wind assessment, with a 20 year track record of use by industry. Although being a model of linear nature, its results can be very accurate even for moderately complex terrain, if model limitations are properly taken into consideration [8].

The meso-micro scale coupling was carried out applying the virtual wind data series to the point where once a local wind measurement was conducted.

\section{Test Case}

In order to verify if the results of the methodology are accurate enough, namely those coming from WRF, a test case was run. The case study is the preliminary assessment of the wind potential of a site with complex terrain, located in Bulgaria. For reasons of confidentiality of the project the site will not be identified.

The first step was the selection of the representative annual period taken from NCEP/NCAR database. The yearly wind speed deviation from the correspondent 30 years average value calculated for each specific grid area, at surface level, was determined (figure 1) with the objective to find the year which best describes the mean climate conditions on the desired region, in term of wind intensities.

The years that exhibit an annual average wind speed closer to the 30 years average are 1981, 1982, 1990, 2001, 2006, being the 1990 the more representative, and the one selected for this case test.

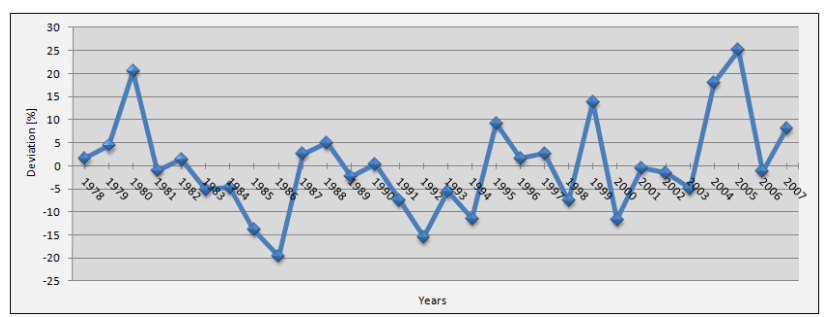

Fig.1. Velocity deviation (in percentage) of annual mean to 30 years long term mean.

The virtual data set, used on mesoscale simulations, has a sampling rate of 10 minutes and corresponds to the simulated full year of 1990, taken at $23 \mathrm{~m}$ (a.g.1.) according to a horizontal resolution of $3 \mathrm{~km}$, thus being valid for every point in a square with $9 \mathrm{~km}^{2}$ area.

The coupling of mesoscale data with microscale linear model WAsP was made considering the "virtual" wind data in the exact point where the local met station was installed.

\section{A. Wind regime characterization}

In order to characterize the wind regime in the implementation area of the wind farm two sets of data were compared. The virtual data set obtained by mesoescale and the records of the local met station.

The local wind data came from a measurement campaign conducted between June 2006 and May 2008 on site, in a met station equipped with two levels of instrumentation: 10 and $20 \mathrm{~m}$ a.g.1..

A summary of the main statistical parameters of the wind for both situations is shown in Table I and in Figures 2 and 3 the wind rose and frequency distribution histogram are presented. 
The virtual data set has an average annual speed of $4.9 \mathrm{~m} / \mathrm{s}$ and the local records of $6.0 \mathrm{~m} / \mathrm{s}$. Isolating the inter annual variability (Figure 1), the mesoescale modulation has indicate a value for the annual mean wind speed of about $10 \%$ less than the one measured on the local station, at the same high. These results will be reflected in the significant higher value obtained for the power density when local measurements data was used.

The frequency wind roses are quite similar when taking into account one or another set of data. The most frequent direction of wind appears to be Wes-Southwest.

For both situations, the histogram of frequency distribution of velocities shows that the most frequent wind speeds, in the study area, are located in the interval [3.0 to 7.0 ] $\mathrm{m} / \mathrm{s}$. Similar shape factor, K, of Weibull distribution was obtained in both sets.

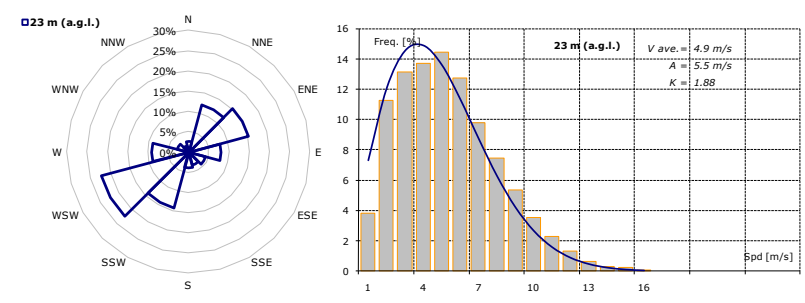

Fig. 2. Wind rose and frequency distribution histogram at virtual wind data, $23 \mathrm{~m}$ a.g.1., 1990

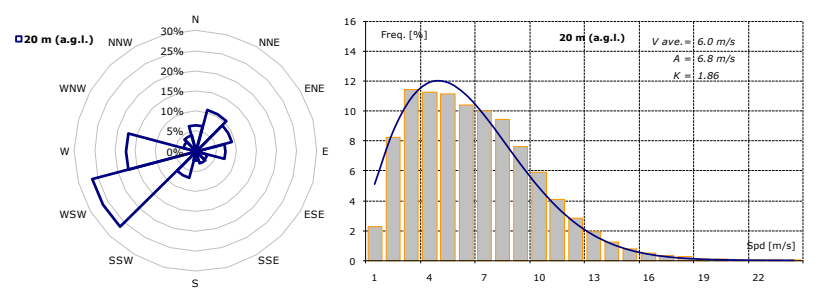

Fig. 3. Wind rose and frequency distribution histogram at met. mast, 20 m a.g.l., June 2006 to May 2008

Concerning to the sector wise mean wind speed and contribution to total energy density different results were obtained from local meteorological data and mesoscale model, as can be seen in Figures 4 and 5.

The stronger winds are felt in the WSW direction and in $\mathrm{N}$ and $\mathrm{W}$ direction in the case of measured data while, the mesoscale model indicates that the sectors with higher wind speeds are between NNE and SSE.

The most energetic sector, obtained taking into consideration the frequency and velocity roses are WSW for the local measurements data set and, for the virtual data set the same added with the NNE and ENE sectors.

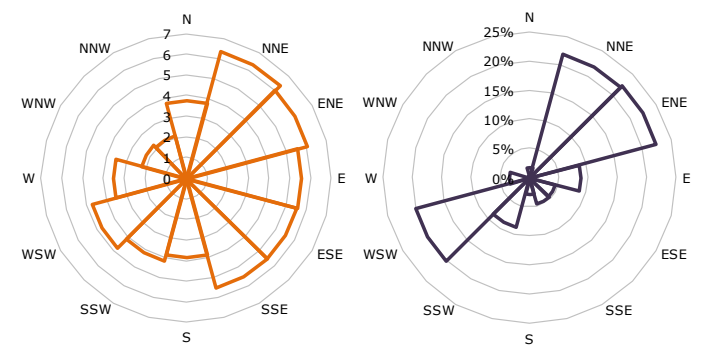

Fig.4. Sector wise mean wind speed and contribution to total energy density at virtual wind data, $23 \mathrm{~m}$ a.g.l.

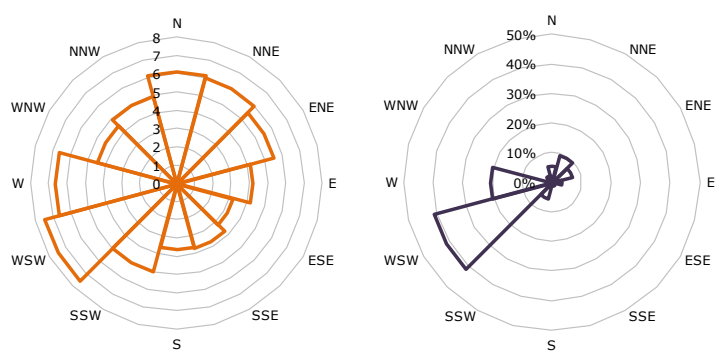

Fig.5. Sector wise mean wind speed and contribution to total energy density at met. mast, $20 \mathrm{~m}$ a.g.l.

\section{B. Production estimates}

For the production estimates purpose four different kind of inputs must be considered: topography and roughness characterization of the terrain, restrictions to the implementation of the wind farm, reference turbine and, finally, the set of data.

The digital representation of topography (Figure 6) was based on military maps 1:50 000 obtained from the program SRTM (Shuttle Radar Topography Mission) from NASA, with lines at $10 \mathrm{~m}$. In the figure are marked the local meteorological station localization and the $3 \times 3$ $\mathrm{Km}$ area of model resolution applied.

Table I. - Summary characteristics of wind data

\begin{tabular}{|cccccccccccc} 
& $\begin{array}{c}\text { Heigth } \\
{[\mathbf{m}]}\end{array}$ & \multicolumn{2}{c}{ Recovery Rates [\%] } & $\begin{array}{c}\text { Mean } \\
\text { Wind Spd }\end{array}$ & \multicolumn{2}{c}{ Weibull } & \multicolumn{2}{c}{$\begin{array}{c}\text { Mean Turb. } \\
\text { Intensity }\end{array}$} & $\begin{array}{c}\text { Max. } \\
\text { Wind Spd }\end{array}$ Max. Gust & $\begin{array}{c}\text { Power } \\
\text { Dm/s] }\end{array}$ & $\begin{array}{c}\text { Density } \\
{\left[\mathbf{W} / \mathbf{m}^{2}\right]}\end{array}$ \\
\hline $\begin{array}{c}\text { Virtual wind } \\
\text { data }\end{array}$ & 23 & $99.9 \%$ & $99.9 \%$ & $99.9 \%$ & 4.9 & 5.5 & 1.88 & - & 16.0 & - & 145 \\
\hline Met. mast & 20 & $93.8 \%$ & $97.7 \%$ & $93.8 \%$ & 6.0 & 6.8 & 1.86 & $8.0 \%$ & 41.3 & 36 & 278 \\
\hline
\end{tabular}

\begin{tabular}{ccccc}
\multicolumn{5}{c}{ Temperature $\left[{ }^{\circ} \mathbf{C}\right]$} \\
\hline $\begin{array}{c}\text { Heigth } \\
{[\mathbf{m}]}\end{array}$ & $\begin{array}{c}\text { Recovery } \\
\text { Rate }[\%]\end{array}$ & Mean & Maximum & Minimum \\
\hline 23 & $99.9 \%$ & 7.0 & 24.7 & -13.4 \\
\hline 20 & $94.8 \%$ & 5.4 & 28 & -20.4 \\
\hline
\end{tabular}




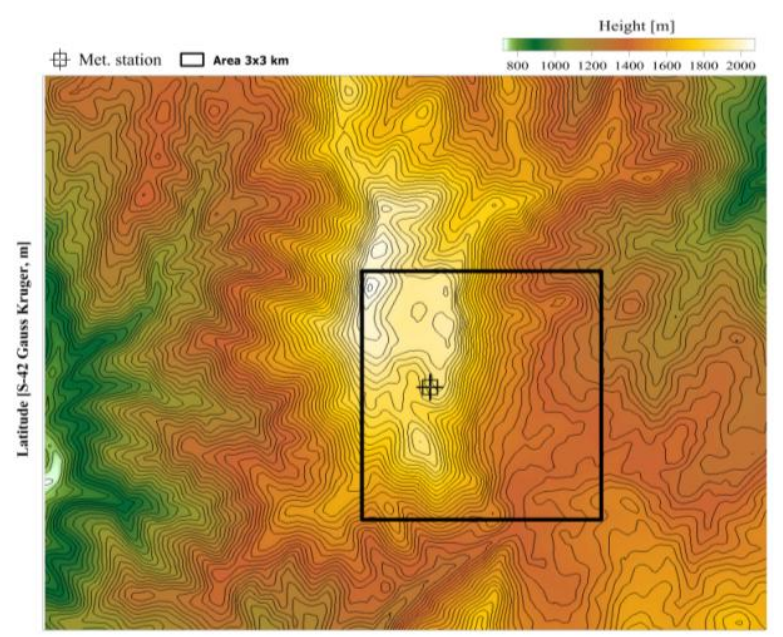

Longitude [S-42 Gauss-Kruger, m]

Fig. 6. Digital elevation model

The area in question is a mountainous area presenting altitudes of around 2000 meters. The terrain complexity indicates that the results of the estimates must be handle with care once that they were obtained with a linear model, WASP, and therefore can have a considerable uncertainty.

An indication of this complexity can be seen in Figure 7 where the area with slopes above $25 \%$ is plotted. Despite the altitude information provided by NASA has not enough detailed to be calculated accurately the areas with marked pending, this information can give an idea about the complexity of the terrain and the limited space available for project implementation once that the turbines cannot be positioned in locations with greater slopes than the limit plotted.

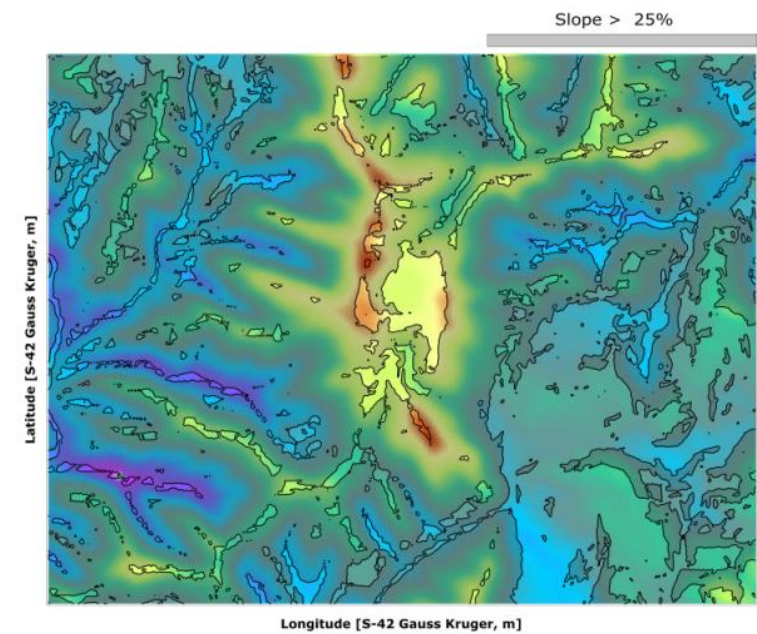

Fig. 7. Area with slopes above $25 \%$

For the generality of the studded area, occupation and land cover was assumed to be mostly composed of shrubsized moderate to high (trees with heights varying between 8 and 26 meters) and therefore within the class 3 of roughness according to the European Atlas wind, and with an assumed uniform roughness length values of $0.7 \mathrm{~m}$.

The main characteristics of the turbine selected for the calculations are presented in Table II.
Table II. - Main wind turbine characteristics

\begin{tabular}{|c|c|c|c|c|c|c|c|}
\hline \multirow[b]{2}{*}{ Manufacturer } & \multirow[b]{2}{*}{ Model } & \multirow{2}{*}{$\begin{array}{l}\text { Rated } \\
\text { power } \\
{[\mathrm{Mw}]}\end{array}$} & \multirow{2}{*}{$\begin{array}{c}\text { Rotor } \\
\text { diameter } \\
{[\mathrm{m}]}\end{array}$} & \multirow{2}{*}{$\begin{array}{c}\text { Hub } \\
\text { height } \\
{[\mathrm{m}]}\end{array}$} & \multicolumn{2}{|c|}{ Operating range } & \multirow[b]{2}{*}{$\begin{array}{c}\text { Safety class } \\
\text { [IEC 61400] }\end{array}$} \\
\hline & & & & & $\begin{array}{l}\text { Cut-in } \\
{[\mathrm{m} / \mathrm{s}]} \\
\end{array}$ & $\begin{array}{c}\text { Cut-out } \\
{[\mathrm{m} / \mathrm{s}]}\end{array}$ & \\
\hline Repower & MM92 & 2.0 & 92.5 & 80 & 3 & 24 & IIa \\
\hline
\end{tabular}

The mesoescale virtual series was used to simulate the wind resource over the area under analysis, with the help of WASP model. The obtained results using the data collected locally and the virtual series results in qualitatively equivalent mapping resource.

Figures 8 and 9 shows two mapping concerning to the distribution of annual average wind speed and to the production in hours at full load, estimated at $80 \mathrm{~m}$ a.g.l. (height of the axis of the rotor model turbine considered). The maps presented were made considering an square grid of $50 \times 50 \mathrm{~m}$ where in each node the two variables, mean wind speed and production, were calculated.

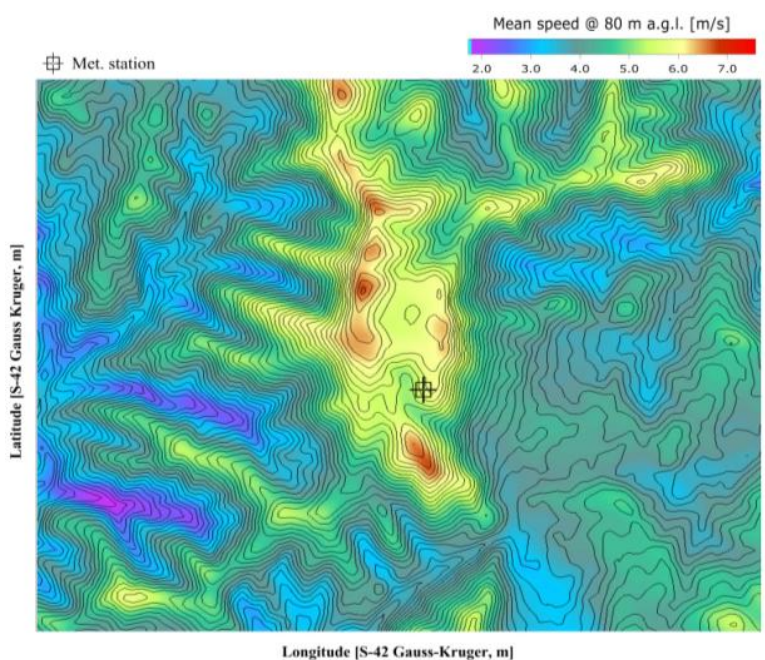

Fig. 8. Annual average wind speed distribution at $80 \mathrm{~m}$ a.g.1.. Based in virtual wind data, $23 \mathrm{~m}$ a.g.l..

In the area under analysis, at $80 \mathrm{~m}$ above the ground, the wind speeds varies between 2.0 and $7.0 \mathrm{~m} / \mathrm{s}$, and the higher speeds were verified in the ridge area with values between 6.0 and $7.0 \mathrm{~m} / \mathrm{s}$, as expected.

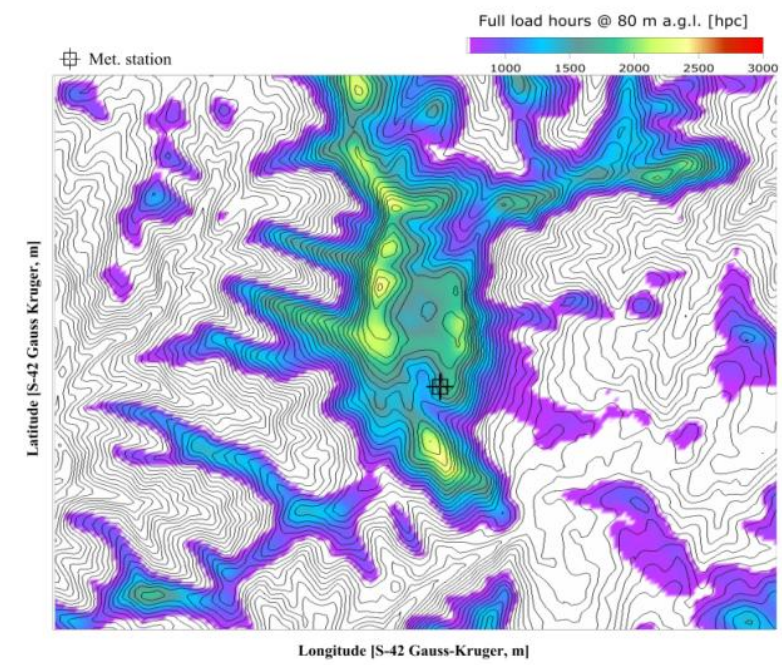

Fig. 9. Annual production, in full load hours, for Repower MM92, $80 \mathrm{~m}$ hub height. Based in virtual wind data, 23 m a.g.l. 
In terms of production the results indicates, for the area of interest, values between $2000 \mathrm{flh}$ to $2400 \mathrm{flh}$.

With the indication of the most productive areas given by the previous presented maps, taking into account the excessive slopes restriction and assuming a distance between turbines of at least 3 rotor diameters, in the direction perpendicular to the most energetic one, a preliminary layout was defined. This configuration is presented in Fig. 10 over the wind speed distribution. It is composed by 10 Repower MM92 wind turbines of $2 \mathrm{MW}$ more or less aligned with the fest of the mountain, in a $20 \mathrm{MW}$ capacity project.

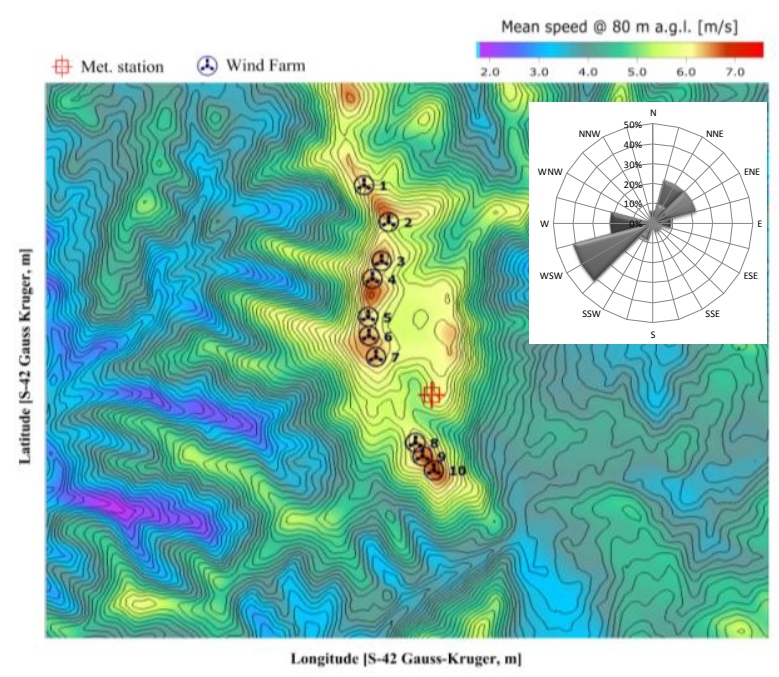

Fig. 10. Wind resource and preliminary layout for Repower MM92 with $80 \mathrm{~m}$ of hub height.

The electric energy production was then estimated taking into account the two sets of data, virtual and locally measured. The results are summarised on Table III.

Table III. - Production estimates from the two data sets

\begin{tabular}{ccccccc} 
& \multicolumn{5}{c}{ Annual Energy Yiel } \\
\cline { 2 - 6 } Wind Farm & $\begin{array}{c}\text { Power } \\
\text { MW }\end{array}$ & $\begin{array}{c}\text { Gross } \\
\text { MWh }\end{array}$ & $\begin{array}{c}\text { Wake } \\
\text { losses } \\
\%\end{array}$ & $\begin{array}{c}\text { Parque } \\
\text { MWh }\end{array}$ & $\begin{array}{c}\text { Full load } \\
\text { hours }\end{array}$ \\
\hline $\begin{array}{c}\text { Virtual } \\
\text { wind data }\end{array}$ & $\begin{array}{c}10 \mathrm{x} \\
\text { Repower } \\
\text { MM92 }\end{array}$ & 20.0 & 43138 & 3.6 & 41590 & 2080 \\
\hline $\begin{array}{c}\text { Met. } \\
\text { Station }\end{array}$ & $\begin{array}{c}10 \mathrm{x} \\
\text { Repower } \\
\text { MM92 }\end{array}$ & 20.0 & 66785 & 2.84 & 64887 & 3244 \\
\hline
\end{tabular}

As the comparison made with the two data sets for wind speeds at the local met mast location indicates, there is a significant difference between the estimates considering the two sources of input data. In fact, the power density has a cubic relation with the wind speed, and thought the difference found, in terms of production is in the magnitude of $35 \%$.

\section{Conclusion}

The study here presented has the main objective of testing a mesoscale approach to the preliminary wind potencial evaluation.
Some limitations to this methodology applied in complex terrains must be pointed. For one hand, the mesoescale resolution of $3 \times 3 \mathrm{~km}$ commonly used could be not enough to properly characterise the wind resource. For the other hand, the microescale model used, WASP, is a linear type and the terrain complexity can induce the model to be work outside its envelope.

Having the previous statement in mind, the results here presented indicates that the use of a mesoscale approach for wind resource assessment purpose must be taken with extremely care. Particular attention should be given to the meso-microscale coupling technique.

For the test case presented, the difference between annual mean wind speed taking into consideration the virtual data series obtained by mesoscale and the local wind measurements was around $10 \%$ less for the first. This figure is amplified when the power density calculation is care. The mesoscale modeling indicates an under estimation of about $35 \%$ in production when compared with the prevision made with the local measurements.

This means that if a preliminary wind potential assessment was made by a mesoscale approach before the local characterization of the wind regime in the area, the project could even be abandoned due to the indication of a small wind potential. Nevertheless, after one year of local measurements the site seems to be quite promising, with a production estimate of about 3250 full load hours.

\section{References}

[1] Kalnay et al.,The NCEP/NCAR 40-year reanalysis project, Bull. Amer. Meteor. Soc., 77, 437-470, 1996

[2] G. O. Chagas, R. Guedes, M. D. O. Manso, Estimating Wind Resource Using Mesoscale Modeling: EWEC 2009 proceedings. European Wind Energy Association.

[3] Skamarock W. C., J. B. Klemp, J. Dudhia, D. O. Gill, D. M. Barker, W. Wang, and J. G. Powers, A description of the Advanced Research WRF Version 2. NCAR Tech Notes468+STR, 2005.

[4] Verdin, K.L., and Greenlee, S.K., Development of continental scale digital elevation models and extraction of hydrographic features. In: Proceedings, Third International Conference/Workshop on Integrating GIS and Environmental Modelling, Santa Fe, New Mexico, January 21-26, 1996. National Centre for Geographic Information and Analysis, Santa Barbara, California.

[5] Anderson, J.R., Hardy, E.E., Roach J.T., and Witmer R.E., A land use and land cover classification system for use with remote sensor data: U.S. Geological Survey Professional, 1976, Paper 964, 28 p..

[6] Olson, J.S., Global ecosystem framework-definitions: USGS EROS Data Centre Internal Report, Sioux Falls, SD, 1994, $37 \mathrm{p}$.

[7] N. Mortensen, L. Landberg, I. Troen, Erik Petersen, Wind Atlas Analysis and Application Program (WASP), 1993.

[8] Troen, I. and E.L. Petersen, European Wind Atlas. Ris $\varnothing$ National Laboratory, Roskilde. ISBN 87-550-1482-8,1989 $656 \mathrm{pp}$. 